Tropical Journal of Pharmaceutical Research November 2021; 20 (11): 2451-2457

ISSN: $1596-5996$ (print); 1596-9827 (electronic)

(C) Pharmacotherapy Group, Faculty of Pharmacy, University of Benin, Benin City, 300001 Nigeria

Available online at http://www.tjpr.org

Original Research Article

http://dx.doi.org/10.4314/tjpr.v20i11.30

\title{
Cardiovascular calcification in chronic kidney disease: Risk factors and effect of $\alpha$-keto acid tablets
}

\author{
Ning Xiang ${ }^{1 *}$, Haijun Liao ${ }^{2}$, Zichen Zhai' ${ }^{2}$, Jingwen Gong ${ }^{2}$ \\ ${ }^{1}$ Department of Geriatrics, Affiliated Hospital of Guizhou Medical University, ${ }^{2}$ Guizhou Medical University, Guizhou 550004, \\ China \\ *For correspondence: Email: kan6mw@163.com
}

Sent for review: 17 July 2021

Revised accepted: 5 October 2021

\begin{abstract}
Purpose: To investigate the effect of $\alpha$-keto acid tablets, and risk factors for cardiovascular calcification in patients with chronic kidney disease (CKD).

Methods: A total of 128 CKD patients were enrolled in this study. They were randomly assigned to study and control groups, each with 64 patients. Control patients received symptomatic treatment, while the study group patients received $\alpha$-keto acid tablets plus. Indices of cardiovascular calcification, blood lipids and mineral metabolism were determined in the 2 groups of patients and compared. Risk factors for cardiovascular calcification were also analyzed.

Results: After treatment, the two groups had decreased CACS scores and reduced serum FGF-23 levels, with lower values in patients in the study group. Levels of Klotho and fetuin-A were significantly elevated after treatment, with higher values observed in study group patients. The degree of cardiovascular calcification was markedly lower in study group than that in controls. There was no significant difference in blood Ca level between the control and study groups before and after treatment. Logistic multivariate analysis demonstrated that hyperlipidemia, hyperphosphatemia, hypercalcemia, hypertension and diabetes put patients at risk for cardiovascular calcification.

Conclusion: Compound a-keto acid tablets delay cardiovascular calcification in patients with CKD, and alleviate symptoms of related risk factors for cardiovascular calcification.
\end{abstract}

Keywords: Compound a-ketoacid tablets, Chronic kidney disease, Cardiovascular calcification, Risk factors

\begin{abstract}
This is an Open Access article that uses a funding model which does not charge readers or their institutions for access and distributed under the terms of the Creative Commons Attribution License (http://creativecommons.org/licenses/by/4.0) and the Budapest Open Access Initiative (http://www.budapestopenaccessinitiative.org/read), which permit unrestricted use, distribution, and reproduction in any medium, provided the original work is properly credited.
\end{abstract}

Tropical Journal of Pharmaceutical Research is indexed by Science Citation Index (SciSearch), Scopus, International Pharmaceutical Abstract, Chemical Abstracts, Embase, Index Copernicus, EBSCO, African Index Medicus, JournalSeek, Journal Citation Reports/Science Edition, Directory of Open Access Journals (DOAJ), African Journal Online, Bioline International, Open-J-Gate and Pharmacy Abstracts

\section{INTRODUCTION}

Chronic kidney disease (CKD) is one of the most common chronic ailments at present, with a prevalence of about $5-10 \%$, and it is associated with heavy burden on global public health resources [1,2]. Cardiovascular calcification is a common complication in patients with CKD, and it may be fatal for patients with terminal-stage renal ailment [3]. A prospective study on 110 maintenance hemodialysis patients with cardiovascular risk showed that each 1-point increase in carotid calcification score resulted in a 2.6-fold increase in death risk [4].

Nonetheless, there is no effective treatment for cardiovascular calcification in patients with CKD. 
Conventional treatment is applied using low protein diet to prevent and treat kidney damage caused by proteins [5]. Cardiovascular calcification in CKD patients is attributed to disorders in mineral metabolism. Studies have demonstrated that $\alpha$-keto acid tablets are calcium salts which regulate disorders in calcium and phosphorus metabolism in patients $[6,7]$. However, there are no studies on the suppressive effect of compound $\alpha$-keto acid tablets on cardiovascular calcification process in patients with CKD.

Therefore, this study was carried out to provide effective treatment guide for cardiovascular calcification in patients with CKD through investigation of the effect of compound $\alpha$-keto acid tablets on cardiovascular calcification process in these patients.

\section{METHODS}

\section{Patients}

A total of 128 patients with CKD were recruited from July 2016 to March 2019, as research subjects. The diagnosis of CKD was based on National Kidney Foundation/ Kidney Disease Outcome Quality Initiative (NKFK/DOQI) classification standard [8]. Glomerular filtration rate (eGFR) was measured as stipulated in Modification of Diet in Renal Disease (MDRD). The patients comprised 73 males and 55 females, and they were assigned to study and control groups ( $n=64$ each).

Patients with acute infection or trauma, those with severe cardiovascular and cerebrovascular diseases, malignant tumors or blood diseases; and patients with obvious mental disorders were excluded from the study. All patients signed informed consent form. The study was approved by the institutional ethics committee of Affiliated Hospital of Guizhou Medical University, Guizhou, China (approval no. = GZ15038864). The protocol used in the study was in line with the guidelines for human studies in the Declaration of Helsinki [9].

\section{Treatments}

All patients were given low-phosphorus and lowprotein diet. Erythropoietin was administered via subcutaneous injection at a dose of 10,000 U/day. Folic acid was given at an oral dose of 5 mg thrice daily. Iron was administered to all patients to maintain hemoglobin $(\mathrm{Hb})$ at normal level, and to correct anemia and acidosis. Symptomatic treatments such as blood pressure control and blood sugar control were administered according to the patients' conditions. Moreover, the study group was treated with compound $\alpha$-keto tablets which were given orally three times a day. Patients in both groups were observed for 6 months.

\section{Measurement of cardiovascular calcification}

Imaging: 64-slice spiral CT was used for plain scanning of the coronary artery. A slice of thickness $5 \mathrm{~mm}$, CT peak $>130 \mathrm{H}$, and calcification area $\geq 1 \mathrm{~mm}^{2}$ was adjudged as positive indication of coronary artery calcification. Coronary artery calcification score (CACS) was calculated as indicated in Eq 1.

CACS $=$ CTpc $\times$ CA

where CTpc is CT peak coefficient, and CA is calcification area.

\section{Determination of serum cardiovascular calcification index}

The levels of fibroblast growth factor (FGF-23), Fetuin-A and Klotho were determined using their respective enzyme-linked immunsorbent assay (ELISA) kits.

\section{Determination of lipid metabolism indices}

Sera from fasting venous blood were subjected to assay of levels of triglycerides (TGs) and total cholesterol (TC) using an automatic Biochemical Analyzer (Thermo Scientific ${ }^{\mathrm{TM}}$ Indiko $^{\mathrm{TM}}$ ).

\section{Determination of mineral metabolism index}

Blood levels of calcium $(\mathrm{Ca})$ and phosphorus $(\mathrm{P})$ were determined in fasted venous bllod using an automatic Biochemical Analyzer, and the calcium-phosphorus product $(\mathrm{Ca} \times P)$ was calculated.

\section{Statistical analysis}

The data obtained in the study were analyzed using SPSS version 19.0 software. Measurement data are presented as mean \pm standard deviation (SD), and were compared between the two groups using Student's $t$-test. Paired $t$-test was used for comparison of data before and after treatment. Counting data are presented as number and percentage [n, (\%)], and were analyzed using chi-squared $\left(X^{2}\right)$ test. Logistic regression model was used to analyze risk factors for secondary cardiovascular calcification. Values of $p<0.05$ were taken as indicative of statistically significant differences. 


\section{RESULTS}

\section{Clinical profiles of patients}

There were no significant differences in gender, age, BMI and CKD types between the control and study groups $(p>0.05)$.

\section{Indices of cardiovascular calcification}

After treatment, patients in the two groups had decreased CACS scores and reduced serum FGF-23 levels, with lower values in study group patients. The levels of Klotho and fetuin-A were significantly elevated after treatment, with higher values in study group. After 6 months of treatment, 21 study group patients had cardiovascular calcification, accounting for an incidence of $32.81 \%$. There were 38 patients cardiovascular calcification in the control group, accounting for an incidence of $59.37 \%$. The incidence of cardiovascular calcification was markedly lower in the study group than in controls.
A

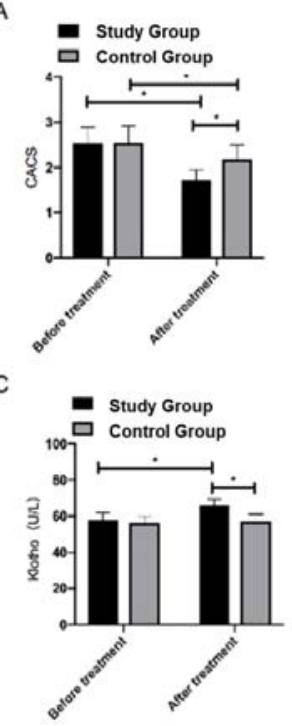

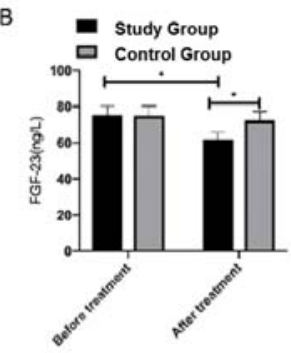

D

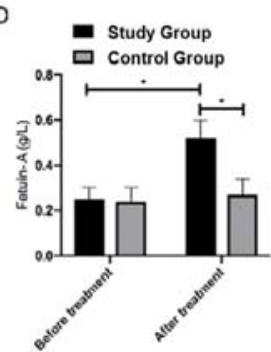

Figure 1: Incidence of cardiovascular calcification. ${ }^{*} P$ $<0.05$

Table 1: Profiles of patients [n (\%)]

\begin{tabular}{|c|c|c|c|c|}
\hline Variable & $\begin{array}{l}\text { Study group } \\
\quad(n=64)\end{array}$ & $\begin{array}{l}\text { Control group } \\
(n=64)\end{array}$ & $x^{2}$ & $P$-value \\
\hline Gender & & & 0.287 & 0.592 \\
\hline Male & 35 (54.69) & $38(59.38)$ & & \\
\hline Female & $29(45.31)$ & $26(40.63)$ & & \\
\hline Age (years) & & & 0.031 & 0.860 \\
\hline$\leq 57$ & $31(48.44)$ & $30(46.88)$ & & \\
\hline$>54$ & $33(51.56)$ & $34(53.13)$ & & \\
\hline BMI $\left(\mathrm{kg} / \mathrm{m}^{2}\right)$ & & & 0.032 & 0.858 \\
\hline$\leq 23$ & $28(43.75)$ & $27(42.16)$ & & \\
\hline$>23$ & $36(56.25)$ & $37(57.81)$ & & \\
\hline Smoking history & & & 0.126 & 0.723 \\
\hline Yes & $30(46.88)$ & $28(43.75)$ & & \\
\hline No & $34(53.13)$ & $36(56.25)$ & & \\
\hline Type of kidney disease & & & 0.130 & 0.988 \\
\hline $\begin{array}{l}\text { Chronic } \\
\text { glomerulonephritis }\end{array}$ & $21(32.81)$ & $20(31.25)$ & & \\
\hline IgA nephropathy & 11(17.19) & $12(18.75)$ & & \\
\hline Diabetic nephropathy & $17(26.56)$ & $16(25.00)$ & & \\
\hline Hypertensive nephropathy & $15(23.44)$ & $16(25.00)$ & & \\
\hline High blood lipid level & & & 0.125 & 0.724 \\
\hline Yes & $34(53.13)$ & $32(50.00)$ & & \\
\hline No & $30(46.88)$ & $32(50.00)$ & & \\
\hline
\end{tabular}




\section{Blood lipid profiles}

After treatment, the levels of TC and TGs in both groups were significantly decreased, while the levels of TC and TGs in the study group were markedly decreased, relative to the control group $(p<0.05)$.
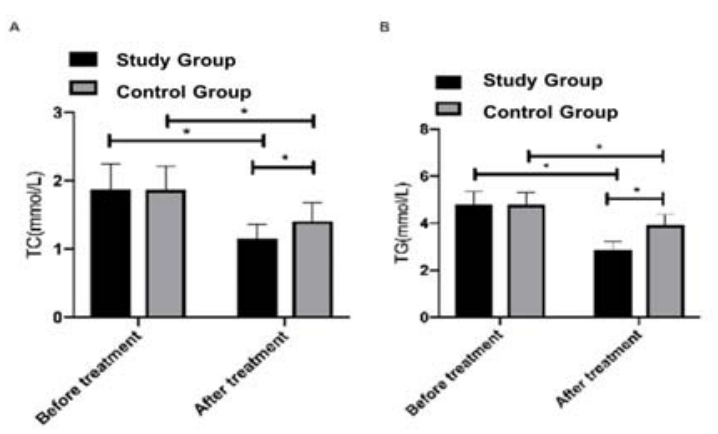

Figure 2: Effect of treatments on blood lipid indexes in the two groups. ${ }^{*} P<0.05$

\section{Mineral metabolism indices}

After treatment, blood levels of $P$ and calciumphosphorus product $(\mathrm{Ca} \times \mathrm{P})$ in both groups were markedly decreased, and their values were markedly lower in study group patients than in controls. There were no significant changes in the blood levels $\mathrm{Ca}$ in both groups $(p>0.05)$. These results are shown in Figure 3.

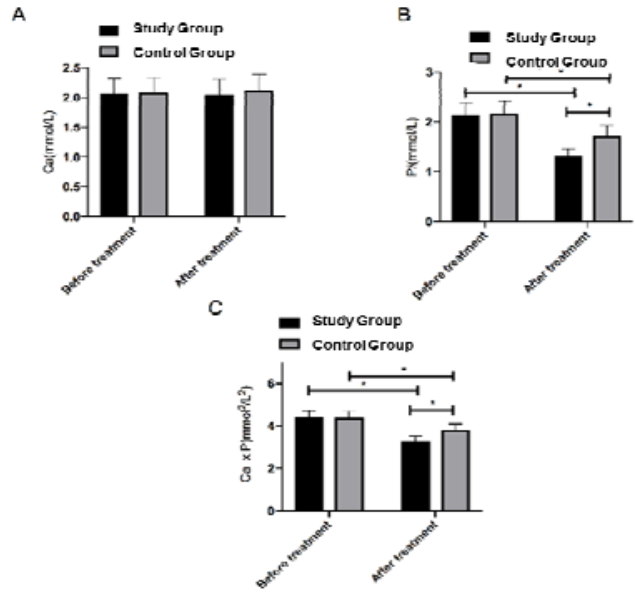

Figure 3: Effect of treatments on mineral metabolism indexes in the two groups. ${ }^{*} P<0.05$

\section{Univariate analysis of secondary cardiovascular calcification in the patients}

Patients with vascular calcification $(n=59)$ and non-vascular calcification patients $(n=69)$ were analyzed. Single factor analysis showed no significant differences in terms of gender and age between both groups $(p>0.05)$. In contrast, the application of compound $\alpha$ ketoacid tablets resulted in significant differences in incidents of hyperphosphatemia, hypercalcemia, hypertension and diabetes $(p<0.05$; Table 2$)$.

Table 2: Univariate analysis of factors likely to have negative impact on patients with hypothyroidism and cardiac insufficiency

\begin{tabular}{|c|c|c|c|c|}
\hline Variable & $\begin{array}{c}\text { Vascular calcification } \\
\text { group } n=59\end{array}$ & $\begin{array}{c}\text { Non-vascular } \\
\text { calcification group } n=69\end{array}$ & $t / x^{2}$ & $P$-value \\
\hline Gender [n, (\%)] & & & 0.054 & 0.816 \\
\hline Male & $33(55.93)$ & $40(57.97)$ & & \\
\hline Female & $26(44.07)$ & $29(42.03)$ & & \\
\hline Age (years) & $57.85 \pm 5.42$ & $57.12 \pm 5.17$ & 0.779 & 0.438 \\
\hline BMI $\left(\mathrm{kg} / \mathrm{m}^{2}\right)$ & $23.05 \pm 1.32$ & $22.75 \pm 1.28$ & 1.303 & 0.195 \\
\hline Smoking history & & & 0.382 & 0.537 \\
\hline Yes & $25(42.37)$ & $33(47.83)$ & & \\
\hline No & $34(57.63)$ & $36(52.17)$ & & \\
\hline $\begin{array}{l}\text { Hyperphosph- } \\
\text { atemia }\end{array}$ & & & 24.38 & $<0.001$ \\
\hline Yes & $47(79.66)$ & $25(36.23)$ & & \\
\hline No & $12(20.34)$ & $44(63.77)$ & & \\
\hline Hypercalcemia & & & 15.17 & $<0.001$ \\
\hline Yes & $42(71.19)$ & $28(40.58)$ & & \\
\hline No & $17(28.81)$ & $47(68.12)$ & & \\
\hline Hypertension & & & 14.46 & $<0.001$ \\
\hline Yes & $32(54.24)$ & $15(21.74)$ & & \\
\hline No & $27(45.76)$ & $54(78.26)$ & & \\
\hline Diabetes & & & 13.26 & $<0.001$ \\
\hline Yes & $36(61.02)$ & $20(28.99)$ & & \\
\hline No & $23(38.98)$ & $49(71.01)$ & & \\
\hline High blood lipids & & & 14.09 & $<0.001$ \\
\hline Yes & $41(69.49)$ & $25(36.23)$ & & \\
\hline No & $18(30.51)$ & $44(63.77)$ & & \\
\hline
\end{tabular}


Table 3: Risk factors for cardiovascular calcification

\begin{tabular}{lllllll}
\hline Variable & $\boldsymbol{\beta}$ & SE & Wald & OR & $\mathbf{9 5} \% \mathbf{C l}$ & $\boldsymbol{P}$ \\
\hline High blood lipids & 0.468 & 0.213 & 4.671 & 1.625 & $1.033-2.411$ & 0.012 \\
$\begin{array}{l}\text { Hyper- } \\
\text { phosphatemia }\end{array}$ & 0.926 & 0.191 & 5.062 & 2.533 & $1.754-3.604$ & $<0.001$ \\
Hypercalcemia & 0.4347 & 0.135 & 9.151 & 1.532 & $1.172-2.033$ & 0.001 \\
Hypertension & 1.064 & 0.458 & 5.262 & 2.988 & $1.145-7.531$ & 0.015 \\
Diabetes & 0.976 & 0.344 & 7.012 & 2.687 & $1.283-5.571$ & 0.005 \\
\hline
\end{tabular}

$\mathrm{SE}=$ Standard Error; OR = Odds Ratio; $\mathrm{Cl}$ = Confidence Interval

Multivariate analysis of factors likely to have negative impacts on patients having hypothyroidism and cardiac insufficiency

Patients with hyperlipidemia, hyperphosphatemia, hypercalcemia, hypertension and diabetes were analyzed, with cardiovascular calcification as dependent variable. Results of logistic regression analysis showed that hyperlipidemia, hyperphosphatemia, hypercalcemia, hypertension and diabetes constituted independent predisposing factors for cardiovascular calcification.

\section{DISCUSSION}

Vascular calcification constitutes a serious threat to the cardiovascular health of patients with kidney disease [10]. Therefore, the risk factors associated with the development of cardiovascular calcification were analyzed in the present study, with a view to providing data which will contribute to the prevention of cardiovascular calcification and reduction in deaths due to cardiovascular disease in CKD patients.

Compound a-keto acid tablet, a compound preparation containing 5 amino acids, 4 keto amino acids (calcium salts), and 1 hydroxy amino acid (calcium salt), provides essential amino acids for patients with CKD through amination or transamination [11]. Moreover, compound a-keto acid tablets produces essential amino acids by interacting with urea nitrogen; it inhibits protein catabolism, and increases the level of amino acid metabolism and metabolic acidosis in vivo [12, 13]. In addition, the calcium component of compound a-keto acid tablets combines with phosphorus in vivo and reduces blood phosphorus levels, thereby improving the metabolism of calcium and phosphorus in patients [14].

In this study, it was found that treatment with compound a-keto acid tablets resulted in marked lowering of blood levels of $\mathrm{P}$ and $\mathrm{Ca} \times \mathrm{P}$ in patients in the study group, when compared with patients in the control group, as well as effective improvement in blood lipid levels of patients, although there were no significant changes in blood Ca levels. A previous study [15] found that calcium salt of keto acid combined with phosphorus in intestinal tract, thereby reducing the absorption of phosphorus. Moreover, the application of compound $\alpha$-keto acid preparation reduced the intake of sulfur and phosphorus amino groups, thereby leading to correction of metabolic acidosis [15]. This also explains how compound a-keto acid tablets reduce the level of $P$ in blood.

Through serum assays and CT examination, it was found that CACS score and serum FGF-23 level were significantly reduced in both groups after treatment, with lower values in the study group. In contrast, the levels of Klotho and Fetuin-A were elevated in the two groups after treatment, with higher levels of Klotho and Fetuin-A obtained in study group patients. Osteoblasts secrete FGF-23, a regulator of calcium and phosphorus metabolism. It influences calcium and phosphorus metabolism by binding to the receptor of Klotho. As the disease advances, FGF-23 resistance and Klotho receptor may decrease, resulting in progressive increases in FGF-23 levels [16]. Klotho receptor inhibits calcification independent of FGF-23, a property which makes it useful as an endogenous inhibitor of vascular calcification [17]. Fetuin-A is a vascular calcification inhibitor which competitively combines with circulating $\mathrm{Ca}$ and $\mathrm{P}$, thereby suppressing their deposition in pathological mineralized tissues, mineralized bone matrix and atherosclerotic plaques [18]. The results obtained in this study suggest that compound a-keto acid tablets may effectively delay cardiovascular calcification through a mechanism involving down-regulation of the expression of FGF-23 expression and upregulation of the expressions of Klotho and fetuin-a.

Furthermore, results from risk factors analysis for cardiovascular calcification revealed that 
hyperlipidemia, hyperphosphatemia, hypercalcemia, hypertension, and diabetes constituted independent predisposing conditions for cardiovascular calcification in CKD patients. A previous research revealed that lipid deposition on the vascular wall is one of the important material bases for cardiovascular calcification [19]. Results from another study showed that the application of compound $\alpha$-keto acid reduced insulin resistance and enhanced the activities of liver lipase and lipoprotein lipase, thereby improving lipid metabolism and reducing cardiovascular calcification [20]. Moreover, it has been reported that hyperphosphatemia and hypercalcemia were risk factors for cardiovascular calcification [21]. The results of the present study suggest that compound $\alpha$-keto acid contributes to mitigation of hyperphosphatemia in CKD patients.

\section{Limitations of the study}

The sample size used in this study was small. Moreover, the follow-up time was short. Therefore, there is need for further clinical studies to validate the findings reported here.

\section{CONCLUSION}

Compound a-keto acid tablets delays cardiovascular calcification in CKD patients and alleviates symptoms of related risk factors for cardiovascular calcification.

\section{DECLARATIONS}

\section{Conflict of Interest}

No conflict of interest associated with this work.

\section{Contribution of Authors}

We declare that this work was done by the authors named in this article, and all liabilities pertaining to claims relating to the content of this article will be borne by the authors. Ning Xiang conceived and designed the study, and drafted the manuscript. Haijun Liao and Zichen Zhai collected, analyzed and interpreted the experimental data. Jingwen Gong revised the manuscript for important intellectual content. All authors read and approved the final manuscript.

\section{Open Access}

This is an Open Access article that uses a funding model which does not charge readers or their institutions for access and distributed under the terms of the Creative Commons Attribution
License (http://creativecommons.org/licenses/by/ 4.0) and the Budapest Open Access Initiative (http://www.budapestopenaccessinitiative.org/rea d), which permit unrestricted use, distribution, and reproduction in any medium, provided the original work is properly credited.

\section{REFERENCES}

1. GBD 2017 Causes of Death Collaborators. Global, regional, and national age-sex-specific mortality for 282 causes of death in 195 countries and territories, 19802017: a systematic analysis for the Global Burden of Disease Study 2017. Lancet 2018; 392(10159): 17361788.

2. Bajaj A, Damrauer SM, Anderson AH, Xie D, Budoff MJ, Go AS, He J, Lash JP, Ojo A, Post WS, et al. Lipoprotein(a) and Risk of Myocardial Infarction and Death in Chronic Kidney Disease: Findings From the CRIC Study (Chronic Renal Insufficiency Cohort). Arterioscler Thromb Vasc Biol 2017; 37(10): 1971-1978.

3. Neven E, De Schutter TM, De Broe ME and D'Haese PC. Cell biological and physicochemical aspects of arterial calcification. Kidney Int 2011; 79(11): 1166-1177.

4. Blacher J, Guerin AP, Pannier B, Marchais SJ and London GM. Arterial calcifications, arterial stiffness, and cardiovascular risk in end-stage renal disease. Hypertension 2001; 38(4): 938-942.

5. Liu D, Wu M, Li L, Gao X, Yang B, Mei S, Fu L and Mei C. Low-protein diet supplemented with ketoacids delays the progression of diabetic nephropathy by inhibiting oxidative stress in the KKAy mice model. Br J Nutr 2018; 119(1): 22-29.

6. Wang $M, X u H$, Chong Lee Shin OL, Li L, Gao H, Zhao Z, Zhu F, Zhu H, Liang W, Qian K, et al. Compound a-keto acid tablet supplementation alleviates chronic kidney disease progression via inhibition of the NF-kB and MAPK pathways. J Transl Med 2019; 17(1): 122.

7. Kudryavtseva AV, Krasnov GS, Dmitriev AA, Alekseev $B Y$, Kardymon OL, Sadritdinova AF, Fedorova MS, Pokrovsky AV, Melnikova NV, Kaprin AD, et al. Mitochondrial dysfunction and oxidative stress in aging and cancer. Oncotarget 2016; 7(29): 44879-44905.

8. Nagai K, Yamagata K, Iseki K, Moriyama T, Tsuruya K, Fujimoto S, Narita I, Konta T, Kondo M, Kasahara M, et al. Antihypertensive treatment and risk of cardiovascular mortality in patients with chronic kidney disease diagnosed based on the presence of proteinuria and renal function: A large longitudinal study in Japan. PLOS One 2019; 14(12): e0225812.

9. Templeman I, Thompson D, Gonzalez J, Walhin JP, Reeves S, Rogers PJ, Brunstrom JM, Karagounis LG, Tsintzas $K$ and Betts JA. Intermittent fasting, energy balance and associated health outcomes in adults: study protocol for a randomised controlled trial. Trials 2018; 19(1): 86.

10. Schrauben SJ, Jepson C, Hsu JY, Wilson FP, Zhang X, Lash JP, Robinson BM, Townsend RR, Chen J,

Trop J Pharm Res, November 2021; 20(11): 2456 
Fogelfeld L, et al. Insulin resistance and chronic kidney disease progression, cardiovascular events, and death: findings from the chronic renal insufficiency cohort study. BMC Nephrol 2019; 20(1): 60.

11. Milovanova SY, Milovanov YS, Taranova MV and Dobrosmyslov IA. [Effects of keto/amino acids and a low-protein diet on the nutritional status of patients with Stages 3B-4 chronic kidney disease]. Ter Arkh 2017; 89(6): 30-33.

12. Jiang N, Qian J, Sun W, Lin A, Cao L, Wang Q, Ni Z, Wan Y, Linholm B, Axelsson J, et al. Better preservation of residual renal function in peritoneal dialysis patients treated with a low-protein diet supplemented with keto acids: a prospective, randomized trial. Nephrol Dial Transplant 2009; 24(8): 2551-2558.

13. Chen W, Guo ZY, Wu H, Sun LJ, Cai LL and Xu HY. [Effects of low-protein diet plus alpha-keto acid on micro-inflammation and the relationship between microinflammation and nutritional status in patients performing continuous ambulatory peritoneal dialysis: a randomized controlled trial]. Zhong Xi Yi Jie He Xue Bao 2008; 6(5): 473-477.

14. Cupisti $A$ and Bolasco P. Keto-analogues and essential aminoacids and other supplements in the conservative management of chronic kidney disease. Panminerva Med 2017; 59(2): 149-156.

15. Garneata $L$ and Mircescu G. Effect of low-protein diet supplemented with keto acids on progression of chronic kidney disease. J Ren Nutr 2013; 23(3): 210-213.
16. Chanakul A, Zhang MY, Louw A, Armbrecht HJ, Miller WL, Portale $A A$ and Perwad F. FGF-23 regulates CYP27B1 transcription in the kidney and in extra-renal tissues. PLoS One 2013; 8(9): e72816.

17. Nordholm A, Mace ML, Gravesen E, Hofman-Bang J, Morevati M, Olgaard K and Lewin E. Klotho and activin $A$ in kidney injury: plasma Klotho is maintained in unilateral obstruction despite no upregulation of Klotho biosynthesis in the contralateral kidney. Am J Physiol Renal Physiol 2018; 314(5): F753-f762.

18. Bostom A, Pasch A, Madsen T, Roberts MB, Franceschini N, Steubl D, Garimella PS, Ix JH, Tuttle $K R$, Ivanova $A$, et al. Serum Calcification Propensity and Fetuin-A: Biomarkers of Cardiovascular Disease in Kidney Transplant Recipients. Am J Nephrol 2018; 48(1): 21-31.

19. Vaziri ND. Dyslipidemia of chronic renal failure: the nature, mechanisms, and potential consequences. Am J Physiol Renal Physiol 2006; 290(2): F262-272.

20. Aparicio M, Bellizzi V, Chauveau P, Cupisti A, Ecder T, Fouque D, Garneata L, Lin S, Mitch WE, Teplan V, et al. Protein-restricted diets plus keto/amino acids--a valid therapeutic approach for chronic kidney disease patients. J Ren Nutr 2012; 22(2 Suppl): S1-21.

21. Chen J, Budoff MJ, Reilly MP, Yang W, Rosas SE, Rahman M, Zhang X, Roy JA, Lustigova E, Nessel L, et al. Coronary Artery Calcification and Risk of Cardiovascular Disease and Death Among Patients With Chronic Kidney Disease. JAMA Cardiol 2017; 2(6): 635-643. 